\title{
Microones en un forn
}

\author{
J. Lorenzo Ramírez Castro \\ IES Maria Rúbies - Lleida \\ jramire7@xtec.cat
}

Es tracta d'un seguit d'experiències molt vistoses per realitzar amb un forn de microones domèstic. Ajuden a entendre què són les microones, com escalfen, per què no escalfen igual totes les substàncies, què passa quan es fica un metall a dins del microones, per què es veu tan malament a través de les seves portes, etc. Fins i tot es calcula la velocitat de la llum.

Encara que sovint es necessita un aparell sofisticat per treballar les microones, hi ha moltes demostracions que poden ser fàcilment realitzades, i amb prou seguretat, utilitzant un forn de microones domèstic dels que estan disponibles en els supermercats a preus ara mateix assequibles. En la fotografia de la fig. 1 es mostra un microones comprat per al laboratori del meu centre en una oferta per $100 €$. En tot cas, és molt aconsellable que el microones tingui control electrònic per poder programar petits intervals de temps (5 - $10 \mathrm{~s})$, cosa que no és possible fer amb els analògics.

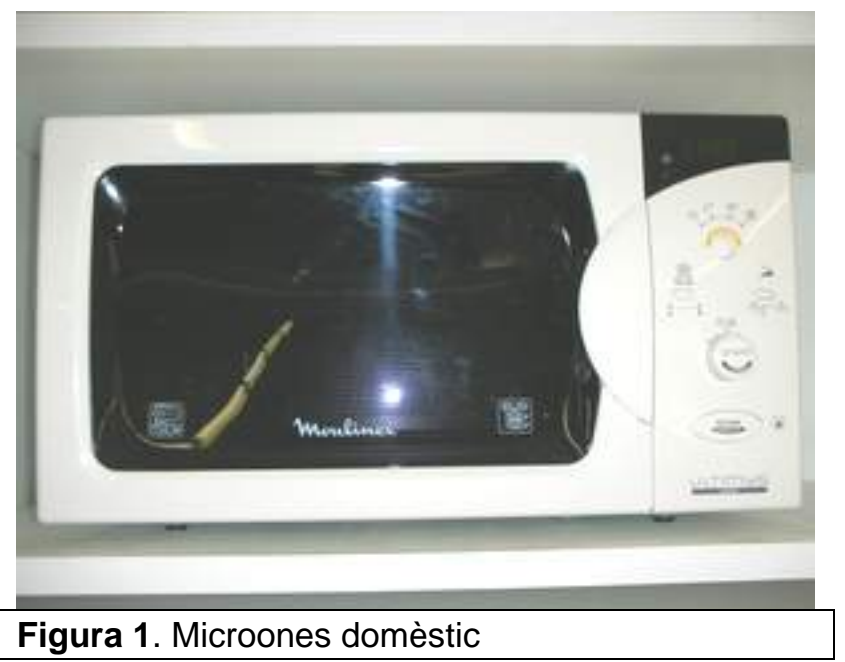

Les experiències que segueixen ajudaran a entendre què són les microones, com escalfen, per què no escalfen igual totes les substàncies, què passa quan es fica un metall a dins del microones, per què es veu tan malament $a$ través de les seves por- tes, etc. Fins i tot podrem calcular la velocitat de la llum.

\section{ATENCIÓ!}

Si es sobrepassa el temps que es té connectat el microones podem tenir conseqüències desagradables o fins i tot perilloses (incendis, alliberament de substàncies tòxiques,...).

Tampoc és recomanable passar gaire temps molt a prop d'un microones connectat.

Cal netejar molt bé el forn si després s'ha d'utilitzar per a la preparació d'aliments.

\section{COM FUNCIONEN ELS FORNS DE MICROONES?}

Aquests forns s'han fet populars perquè cuinen ràpidament, no necessiten recipients addicionals $\mathrm{i}$ són eficients en l'ús de l'electricitat, ja que escalfen el menjar i gairebé res més (no escalfen els plats).

La peça principal del microones és el magnetró (de vegades es veu en la cavitat del forn un rectangle metàl-lic que és la seva antena). El magnetró emet ones electromagnètiques de $2450 \mathrm{MHz}$ de freqüència, 12,2 cm de longitud d'ona i amb una magnitud de camp elèctric d'uns $2 \mathrm{kV} / \mathrm{m}$.

\section{Sobreescalfant}

Tenint en compte que és una activitat molt perillosa, es pot mostrar el fenomen del sobreescalfa- 
ment escalfant un líquid en un vas d'aigua mitjançant un forn de microones. L'aigua s'ha de bullir prèviament, per exemple amb un bunsen, per assegurar que ha estat desgasificada i així reduir la formació de bombolles de gas en l'escalfament al microones.

El vas d'aigua es col-loca en el forn de microones i s'escalfa fins que bulli. Aturem el microones.

\section{Atenció:}

Només s'ha d'agafar el vas amb guants tèrmics i portant ulleres protectores.

Traiem el vas i el col-loquem en un plat per si després arriba a vessar l'aigua. Si aquesta acció es fa amb atenció i ràpidament, l'aigua estarà a una temperatura termodinàmicament inestable entre els 100 i $105^{\circ} \mathrm{C}$

\section{Atenció:}

Molta cura amb les esquitxades i el vessament d'aigua bullent.

Si ara aconseguim punts de nucleació, bé donant un cop al vas o agregant-hi una mica de sucre, es podran formar les bombolles de vapor de l'aigua i l'aigua bullirà espontàniament i violenta.

Val la pena insistir que hem fet l'experiment per mostrar com i per què es produeix aquest fenomen i així evitar accidents a la llar.

Es tracta d'aconseguir, doncs, que els alumnes siguin conscients d'aquest perill i tinguin molt clar que a casa han d'evitar sempre que això pugui passar.

\section{CALEFACCIÓ SELECTIVA}

Els camps elèctrics de les microones només afecten aquelles molècules, anomenades polars, que tenen la seva càrrega elèctrica desigualment distribuïda (amb parts positives i parts negatives), com les d'aigua. En aquest cas una bona fracció de l'energia de les microones es converteix en moviment molecular desordenat, és a dir, en calor, quan les molècules polars tracten de seguir les oscil.lacions del camp.

Si es tracta de molècules no polars (o molt poc; hi ha graus) o estan lligades amb suficient força unes a les altres, no es mouran amb el camp i no hi haurà escalfament a causa de les microones. És el cas de la majoria dels plàstics, vidres o ceràmiques.

1) Introduïm dins d'un forn de microones dos gots amb aproximadament la mateixa quantitat de dos líquids: un de polar, com l'aigua, i un altre de menys polar, com l'oli. Al cap d'un minut possiblement s'hagi posat a bullir l'aigua mentre que l'oli s'haurà escalfat poc.

2) Un altre experiment que confirma el mecanisme d'escalfament citat és posar a escalfar gel. El moviment de translació i rotació de les molècules d'aigua està prou impedit al gel per l'estructura cristal-lina, que manté les molècules prou fixes en certes posicions, motiu pel qual el camp elèctric no pot fer-les moure tan fàcilment i l'escalfament és menys efectiu que a l'aigua líquida. Aquest experiment només funciona bé si el gel està prou eixut.

\section{Efecte d'una sal en dissolució}

L'efecte de la presència d'ions en l'escalfament es pot mostrar escalfant en un microones un vas d'aigua pura i un altre vas que contingui una solució diluïda de clorur de sodi. Es prenen les temperatures dels dos líquids, i ambdós es col-loquen en el mateix forn, on s'escalfen a la màxima potència durant un minut. Després -atenció: les solucions poden estar molt calentes-, es tornen a prendre les temperatures i es comparen. En l'aigua pura, l'escalfament només es produeix per la naturalesa dipolar de les molècules d'aigua, mentre que en l'aigua amb sal hi ha una contribució addicional a la calefacció pel moviment dels ions $\mathrm{Na}^{+} \mathrm{i} \mathrm{Cl}$ en dissolució.

\section{La naturalesa de les microones}

1) Es desconnecta el gir del plat del microones (si no es pot, n'hi ha prou de treure'l o, millor, invertir-lo). Es posa un rectangle de paper tèrmic de fax (millor si està mullat d'aigua). Es connecta el microones fins que s'observa que el paper s'ha ennegrit. S'aprecia que el canvi de color no és uniforme (fig. 2). Per què?

Les microones que utilitza el forn tenen una longitud d'ona d'uns 12,2 cm. Després de ser emeses pel magnetró es reflecteixen a les parets metàl-liques i interfereixen, creant un patró d'ones estacionàries amb màxims i mínims separats per distàncies de l'ordre de mitja longitud d'ona. 


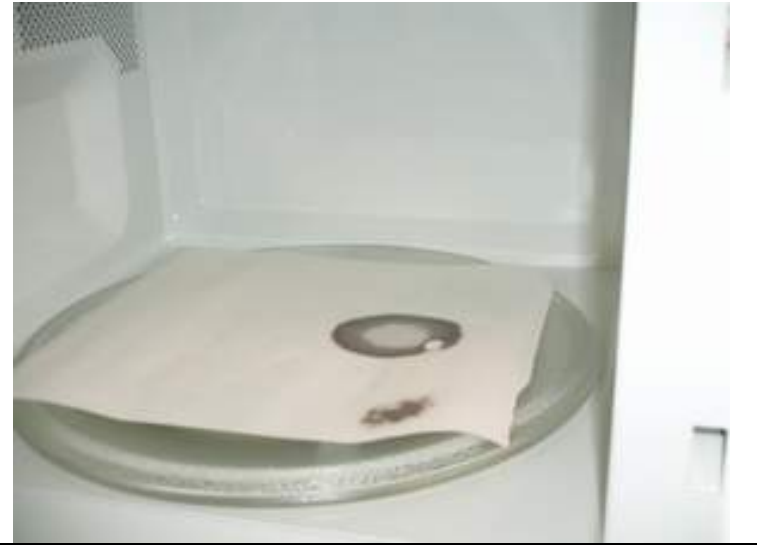

Figura 2. Ennegriment del paper de fax

Precisament d'ordinari es fa girar plat per passejar els aliments perquè tots els seus punts participin en l'absorció d'energia més o menys en igual grau (fig. 3).

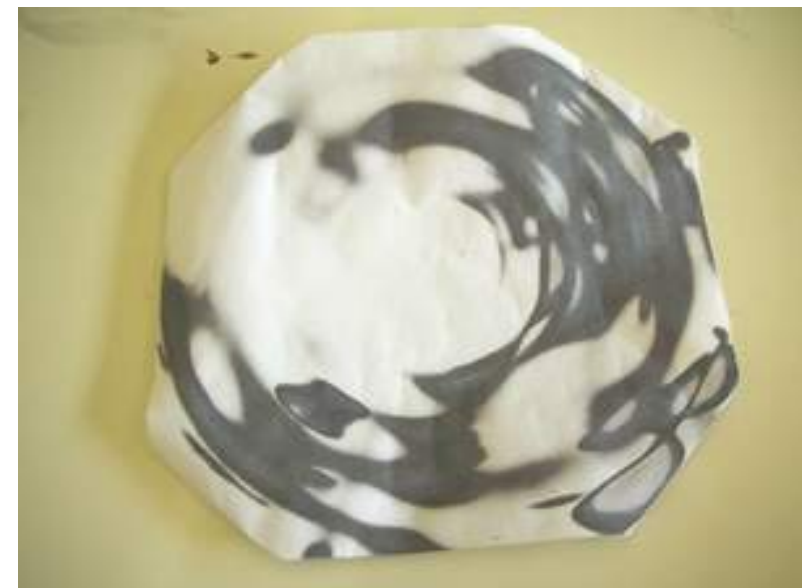

Figura 3. Ennegriment del paper de fax quan gira el plat

2) També es poden posar bocins iguals de núvols dolços en distintes posicions dins del forn sense que el plat giri. S'inflaran, però no ho faran tots en la mateixa mesura.

3) Una altra demostració de la naturalesa de les microones es pot dur a terme utilitzant un tros de paper de filtre que s'hagi mullat amb una dissolució 1,0 $\mathrm{mol} / \mathrm{L}$ de clorur de cobalt (Atenció: és tòxic). Si es manté immòbil en el microones (traient el plat giratori, per exemple) i s'escalfa per un període curt de 15 a 60 s (el temps depèn de la humitat del paper), arriba a ser evident una pauta en el paper.

El clorur del cobalt és de color rosa quan està rodejat per molècules d'aigua i blau quan se li treuen, per exemple escalfant. El paper de clorur de cobalt s'asseca molt més ràpidament en els ventres de l'ona estacionaria que es forma que en els nodes. Un estudi quantitatiu d'aquesta pauta revela que la distància entre els centres de les àrees seques de color blau és aproximadament de $6 \mathrm{~cm}$, el que correspon a la meitat de la longitud d'ona de la microona.

4) Una penúltima possibilitat, que va ser l'estrella de la fira científica Madrid por la Ciencia, l'any 2005, és la d'utilitzar llesques de formatge.

\section{Càlcul de la velocitat de la llum}

Com ja s'ha dit, els forns microones emeten ones electromagnètiques de $2450 \mathrm{MHz}$ de freqüència. Quan es formen les ones estacionàries en l'interior del forn, per a cada longitud d'ona es formen dos ventres, la distància entre els quals és de mitja longitud l'ona $(\lambda / 2)$.

En mesurar amb un regle la distància entre dos ventres consecutius (dues zones contigües de paper de fax més ennegrit o de formatge una mica aixecat, per exemple) sortirà un valor al voltant de $6,1 \mathrm{~cm}$, el que correspondrà a una longitud de la ona estacionària formada de:

$$
\lambda=2 \cdot 6,1=12,2 \mathrm{~cm}=0,122 \mathrm{~m}
$$

A les figures $4 \mathrm{a}$ i $4 \mathrm{~b}$ es veu com els màxims d'energia estan separats per distàncies diferents, tot i que corresponen al mateix forn. El paper de la figura $4 a$ es trobava sobre el plat a la base del microones. En la figura $4 \mathrm{~b}$ es mostra la figura que va sortir quan es va escalfar el paper col-locant-lo sobre el suport elevador del forn.

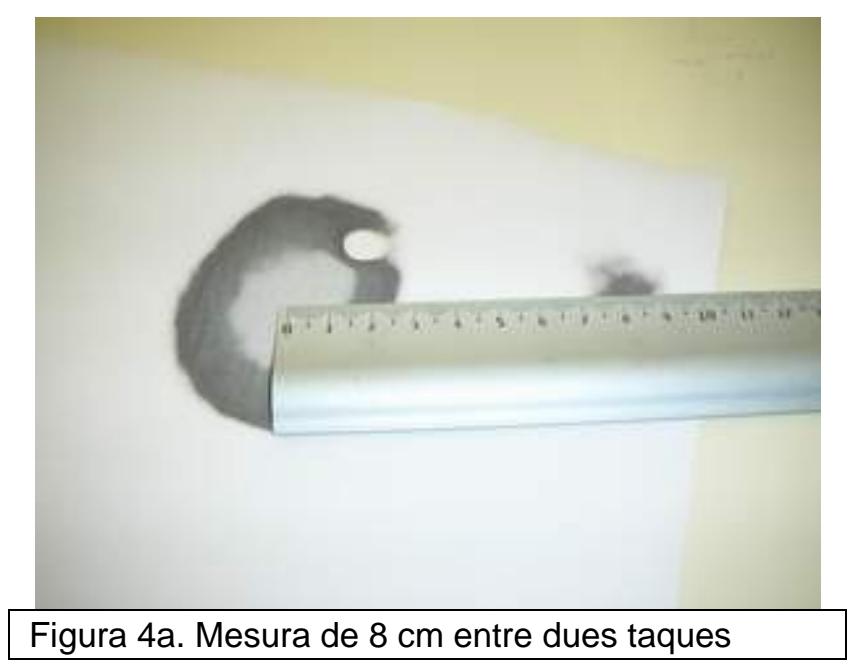




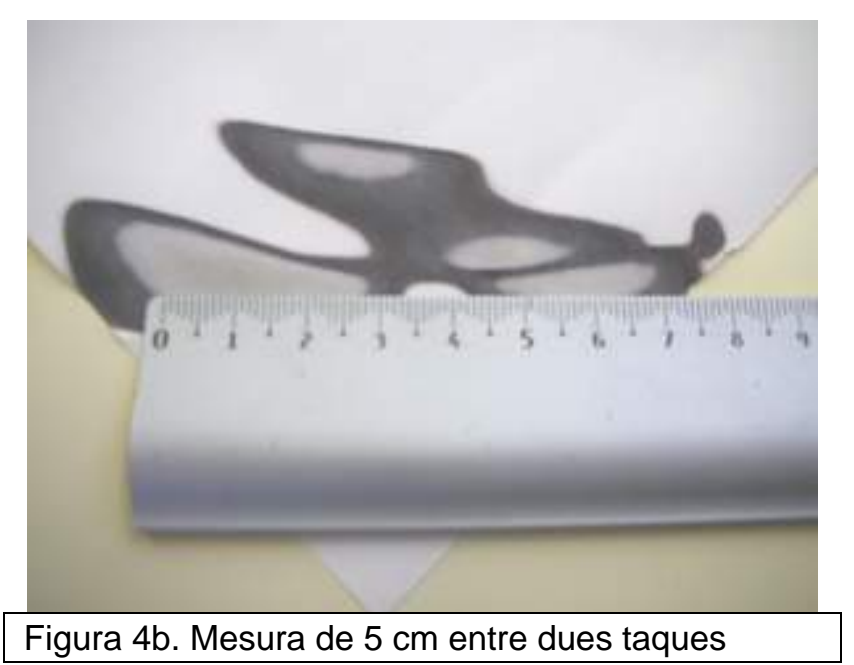

Si es vol quedar bé amb l'alumnat, prèviament s'han de fer proves amb el microones per a localitzar l'altura sobre la base del forn a la que s'ha de ficar el paper per obtenir els $6 \mathrm{~cm}$ entre taques.

Una vegada obtinguda la $\lambda$, no cal sinó utilitzar l'equació de la velocitat de la llum en funció de la longitud d'ona i la freqüència per a calcular-la:

$$
c=\lambda \cdot v=0,122 \times 2450 \cdot 10^{6}=299 \cdot 10^{6} \mathrm{~m} / \mathrm{s}
$$

\section{L'ELECTRICITAT I LES MICROONES}

A continuació es descriuen alguns dels molts experiments que hi ha per a mostrar la relació entre les microones i l'electricitat. Si se'n volen més es pot acudir a les referències del final de l'article. Encara més: és preferible visitar les pàgines web (Hochwald, 1999; Stille, 2005) i veure les fotografies i els vídeos que allí s'esposen, abans d'intentar fer els experiments més laboriosos o perillosos que s'hi proposen.

Per exemple, és preferible veure les fotos del procés d'escalfar un ou dur en un microones i adonar-se de quin és el resultat, que no pas fer-ho un mateix.

\section{Atenció:}

En tots els experiments que segueixen és recomanable no passar de 10 a 15 s amb el microones encès.

Si es vol més temps, és aconsellable posar conjuntament un vas amb aigua en el fons del microones perquè absorbeixi una part de l'energia. Si el microones disposa de la funció descongelació (la potència emesa va de més a menys en el temps), també és aconsellable utilitzar-la. En tot cas, el pro- fessorat haurà de valorar els riscos que comporten aquests experiments abans de decidir si els realitza amb l'alumnat.

També s'ha de recordar que, donat que els objectes s'escalfen molt en aquestes demostracions, és convenient portar guants tèrmics de protecció per retirar els objectes del microones.

\section{Fluorescents}

Introduïm en un microones (a potència màxima, uns 800 - $900 \mathrm{~W}$ ) un tub fluorescent curt recte o circular i engeguem el microones. De seguida el veurem lluir i, una vegada vist, es desconnecta l'aparell ràpidament, perquè no arribi a esclatar el tub.

Perquè un fluorescent s'encengui fa falta que circuli un corrent a l'interior del tub entre els seus dos extrems. Les microones, amb els seus camps elèctrics, proporcionen la diferència de potencial necessària perquè passi el corrent.

\section{Plasma en una bombeta}

Les bombetes també s'encenen en les microones. Donat que la resistència metàl-lica del filament de la bombeta és elevada, ja que està feta a propòsit amb un fil molt fi, es produeix l'escalfament suficient per a posar-la incandescent.

\section{Atenció:}

Es recomana mantenir poc de temps la bombeta dins del forn encesa (només uns segons, just fins que brilli) perquè pot arribar a fondre's el metall de les patilles o fins i tot del propi filament i caure en el vidre, la qual cosa provocarà la ruptura violenta del bulb (fig. 6).

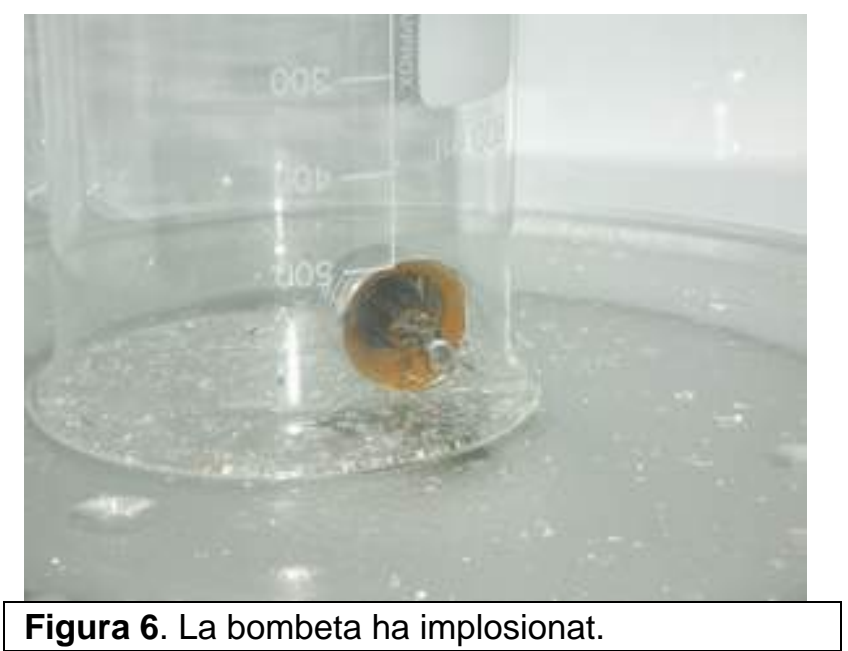




\section{Disc compacte}

Amb qualsevol metall d'alta resistència (fils fins, etc.) ocorrerà el mateix que amb els fluorescents: es produirà un corrent elèctric que generarà un escalfament molt fort, que en algun cas ho fondrà a més de generar petits arcs elèctrics entre distints punts del mateix si hi ha puntes en què es pugui acumular la càrrega. Com es veu, el perillós no és ficar metalls en les microones (les parets són metàl-liques, no?), sinó les altes resistències i les puntes.

Si es fica un fotodiode connectat en sèrie amb una resistència ceràmica elevada el veurem lluir uns instants fins que es fon.

Un experiment curiós relacionat amb l'anterior consisteix en introduir-hi un CD i observar què es veu: una cascada de petites espurnes produïdes per la fusió de les parts metàl-liques de la fina làmina que cobreix el disc compacte (figura 5).
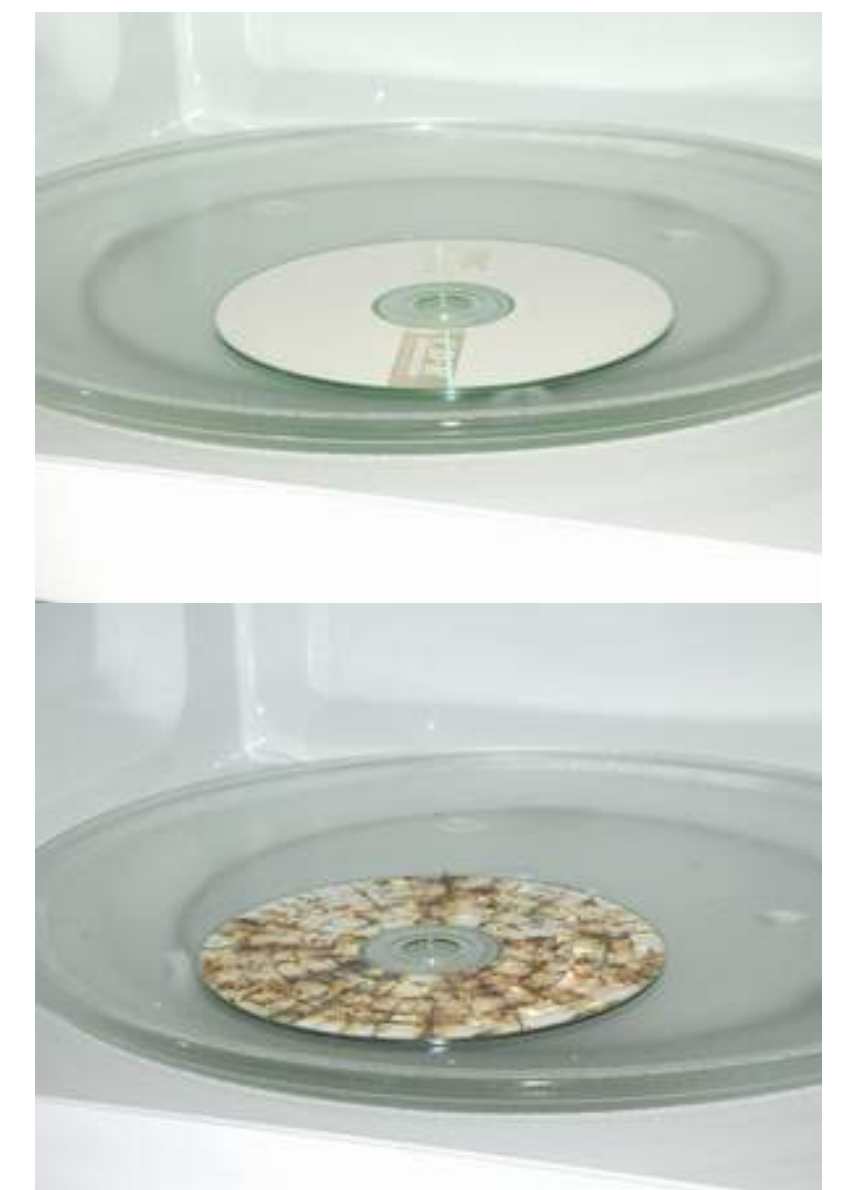

Figura 5. Un CD abans i desprès de passar pel microones

El curiós és que aquest fenomen d'il.luminar-se la bombeta es produeix també si la bombeta està fosa. El gas de baixa pressió dins d'una bombeta pot ser estimulat per la radiació de les microones i engendrar un plasma.

Es col.loca una bombeta en el microones durant no més de 5 - $10 \mathrm{~s}$. Es formarà instantàniament un plasma molt brillant.

\section{Atenció:}

Si es sobrepassa aquest temps, tenint-la-hi, per exemple, durant 20 - $30 \mathrm{~s}$, la bombeta pot arribar a implosionar. L'espectacle és millor (els alumnes aplaudiran), però pot ser perillós. Sempre és convenient cobrir la bombeta amb un vas de precipitats gran per a contenir els vidres trencats (figura 6).

\section{Síntesi ràpida d'aspirina induïda per microones}

Tradicionalment s'ha fet aquesta síntesi en els laboratoris escolars escalfant els reactius a bany maria durant uns minuts i usant àcid sulfúric con a deshidratant. Aquí es proposa una variant amb l'utilització d'un forn microones que produeix la síntesi de l'aspirina més ràpidament, amb més rendiment i que no necessita deshidratant. Si es vol aprofundir, a més a més d'aquesta, Whittaker (2004) proposa realitzar altres reaccions químiques amb el microones.

Es pesen $5 \mathrm{~g}$ d'àcid salicílic en un vas de precipitats de $250 \mathrm{~cm}^{3}$. S'hi agreguen $5 \mathrm{~cm}^{3}$ d'anhídrid etanoic i es cobreix el got amb un vidre de rellotge.

Atenció: totes dues són substàncies irritants.

A continuació es col-loca un altre vas amb 200 $\mathrm{cm}^{3}$ d'aigua al costat del de la mescla de reacció, per absorbir l'excés d'energia del microones.

Es posa en marxa el forn durant uns $60 \mathrm{~s}$. Un cop passats es remena amb cura el contingut i es verifica que la temperatura estigui entre 120 i 130 ${ }^{\circ} \mathrm{C}$.

Atenció: s'hi han d'utilitzar guants i ulleres.

Si la temperatura és més baixa que això, es continua escalfant la mescla fins que s'hagi aconseguit la temperatura apropiada, tenint en compte que les temperatures per damunt de $130^{\circ} \mathrm{C}$ poden produir productes secundaris i reduir el rendiment d'obtenció d'aspirina. 
Es retira el vas fora del microones i es deixa refredar per sota de $100{ }^{\circ} \mathrm{C}$ abans d'abocar-li uns 50 $\mathrm{cm}^{3}$ d'aigua freda. A continuació, s'agita amb una vareta mentre es manté en un bany d'aigua amb gel.

Desprès es filtra i es renta amb aigua freda al buit en un embut buchner i es deixa assecar per l'aire, utilitzar la succió de la trompa buit.

\section{S'escapen les microones del forn?}

En principi, els forns es fabriquen per contenir les microones i impedir que surtin a l'exterior, de manera que només cuinin els aliments que es fiquin dins... i no al cuiner. Per això les seves parets internes són superfícies metàl-liques que reflecteixen les ones electromagnètiques. La porta està formada per dues làmines de plàstic entre les quals es fica una malla metàl.lica amb forats molt petits que actua com una gàbia de Faraday (per això es veu tant malament a través de la porta).

Es pot comprovar si hi ha emissió d'ones a l'exterior col-locant prop de la porta un vas amb aigua $i$ un termòmetre $i$ observant si augmenta la temperatura desprès de fer funcionar el forn durant un temps prolongat (5 minuts, per exemple). Tam- bé es pot posar una ràdio sobre el forn i comprovar en ficar-lo en marxa que no produeix interferències.

Si la protecció dels forns microones impedeix que aquestes ones surtin enfora, també hauria de ser al revés: si es posa un telèfon mòbil o sense fils dins del forn, no hauria de rebre trucades. La realitat és que en tots els forns en els que ho he provat, els mòbils sempre reben el senyal exterior.

La pregunta, doncs, probablement quedarà en l'aire.

\section{Bibliografia}

Hochwald, H., 1999, Microwave Experiments. Pàgina web:

http://apache.airnet.com.au/ fastinfo/microwave/, o http://microwave.tk/

Stille, D., 2005, Electromagnetic Radiation - Microwave Oven - Standing Waves. Pàgina web: http://faraday.physics.uiowa.edu/em/5N10.56.htm

WHITTAKER, G., 2004, Microwave chemistry, School Science Review, Març, 85(312), pàg 87-94. 